\title{
Family Education - Guidelines and Actual Practice in Romania
}

\author{
Maria Pescaru \\ Department of Educational Sciences, Faculty of Education Sciences, Social Sciences and Psychology University of Pitesti, Romania
}

Copyright $\mathrm{C} 2017$ by authors, all rights reserved. Authors agree that this article remains permanently open access under the terms of the Creative Commons Attribution License 4.0 International License

\begin{abstract}
Family education is an essential means of achieving formal education and shows its main characteristics: It is done systematically through life experiences lived concretely, directly; it manifests diffusely in the individuals and groups manifests diffuse conduct of individuals and groups; impregnates the personality with its specific default, integral and continuous influence. In the contemporary approaches of the phenomenon of education, we often discuss about the erosion of the family functions and especially about the social function and, consequently, about the limits on family education, where education is attributed mainly to school.
\end{abstract}

Keywords Family, Education, Actual Practice, Child, Strategies of Families

\section{Introduction}

The family as a social institution in Romania is faced with socio-economic challenges that led to the emergence of social phenomena with direct impact on child education in the family: increased rate of divorce, increase of the mono-parental families, increase of consensual couples, increase of domestic violence, increasing the number of socio-economically disadvantaged families, increasing the number of parents who go abroad to work etc.

Knowing the trends of education as a whole and achieving genuine reform in this area, with beneficial consequences for society as a whole, cannot be achieved without addressing education family to meet these new challenges without correlating changes occurred therein and the effects it causes, with all processes in the society, with changes in education.

\section{The Actual Political Priorities of the Society Regarding the Family Education}

It implicitly aims for education in family and school: the approach education as a main force of changing technology, economy, administration and promotion of values in society; equal access to higher education; high quality education and training knowledge society; transforming education in Romania's modernization resource base; consideration of the investment in human capital as the most profitable in the long term; reducing poverty and social exclusion; improved living standards etc.

The quality of education in the family marks the early development of the individual personality, the chances of school success and subsequent affirmation.

\section{Theoretical Background of Research on Family Education}

The history of life of families in Romania has both continuity and discontinuity - by connecting generational and the change tends to be gradual rather than dramatic; although there are different family patterns and changes from one society to another, however, the family institution remains stable.

Most researchers admit that with the evolution of society, parents-children relations are increasingly defined by an emotional dimension and interest of the parents for children's education increases. Within the educational function of the family - we can detect certain dimensions: instructional-formative; psychosocial; social-integrative; cultural-formative.

Education is understood either as an individual training according to existing social norms and values - serving integration and social order, whether development psycho-individual - according to individual potential, its inclinations and aspirations - help stimulate creativity and social change. 


\section{Educational Strategies of Families}

Pedagogues, psychologists and specialists in social intervention uses the term "family education", but sociologists prefer to talk about "educational strategies families" to emphasize regularity, systemic, coherent, directed the action which has the appearance of an approach rationally conscious (in which actors pursue a goal, choose the appropriate means, assess the results).At the common knowledge level, the idea of "strategy" creates the illusion that the individual is a subject in relation to institutional constraints.

The concept of "educational strategies families" [1] allows disclosure aims, contents (values, attitudes), methods of educational processes which players were family members (parents and children) given that family education is developed as a "pedagogy default" [2] and not as "explicit teaching" [3].

Sociologists consider the pluralism of "the family models" [4] and "educational models" [5] real models. There is no unique, ideal "model" [6] (but not all "models" have the same value).

\section{Elements of the Theoretical Research of Family Education}

The real subject of the educational process is education itself (child, youth); because the Self construction (psycho-social development of the child) implies a correlative dynamic processes of socialization individualization and identification - differentiation, intergenerational transmission of values and norms, and selective breeding is accomplished cultural and social life is intertwined with the change.

Both partners - educator and educated - are active (are agents of action, both in terms of teaching and in the sociological sense, although parents and children are not always aware of the consequences education of their actions, can highlight educational strategies thereof - that appear as the product of negotiations between parents and children.

Family influence is exercised within a network for education agency (family, school, peer group, media etc.); Family educational strategies are the product of interactions and negotiations between the family and other social agents; regardless of what they want agents educational policies which tend to impose a single model of personality, is "prevent" pluralism models that the educational practices they produce and the risk of slipping toward totalitarianism if not open to liberalism educational (for negotiation purposes and means educational action).

\section{Methodological principles of research on family education}

The various theories and hypotheses about the family and education, differentiated by several criteria:

- There is no socio-pedagogical research or even surveys to reveal the current trends clearly outlined on family education in Romania.

- The main axis of the education family has one pole morality (understood as a liability to each other, but also as an area of "minor rules" [7] of meeting face to face), and the opposite culture / teaching (provided training) and civilization (on nutrition, posture, politeness etc.).

- Recent research has led to refute the main thesis circulated in common knowledge and scientific: powerful family thesis, main/unique responsible of failures in child development; helpless family thesis, whose powers would be transferred to state institutions.

The Study of the family diversity diversitatii familiei rises its value if: we are more sensitive to the intersection of various dimensions of diversity (social, economic, cultural) and use a complex, interdisciplinary methodology; expand the definition (s) so as to cover family present realities and put greater emphasis on family procesual exploring attitudes, meanings and the meanings that actors family gives them their decisions and actions; combine research data with reflexivity, with a more global interpretation studied fragment of reality, accepting pluralism beyond the comprehension of certain data that are still partial;

In the context of social change, felt in family life (changes in the structures, functions, roles and statuses family socio-) scientific research education in the family can help transform mentalities parental and family, parental conscience formation and thus to expedite the improvement of education informal (family) and formal (in school) - from the perspective of lifelong learning, linkages between educational levels and forms of education.

\section{Documentary Analysis of Family Education Studies}

The degree of coherence between social and educational projects and everyday practices cannot be revealed by observations or opinions, but through in-depth analyzes that require human and material investment, time and wisdom to ask / operate such analyzes.

The most important benchmarks are: dominant practices of education. coherence, cohesion, distribution of roles; the distribution of roles between parents in terms of gender, features of a mainly traditional family; control authority and the decision belong, in general, to mother; worsening socio-cultural conditions lead to overloading mother with tasks in the child's education; the child participates in taking all these decisions; at the preadolescent age, the child is a psychosocial agent of his own development; parents tend to punish the child especially in relation to educational success; communication between parents and 
children on topics related to their everyday life (schoolwork, activities with friends), but also on topics of great interest to this stage age (child's future, friendship, love, sexuality) is largely deficient.

\section{Socio-educational Risk Factors in the Current Romanian Family}

In the Romanian family there may be several risk factors: financial and economic precariousness; family conflicts propensity generated by poverty, promiscuity morality rate deviant behaviors among parents and preadolescents, especially in rural areas; not only the child creates problems in the family, but the strained relations between members of the family group; the weakening of parental control; problems with the child in school work plan, but also in that of deviant behavior; deviant parental behaviors. In this case we are dealing with dysfunctional families, strongly characterized by severe conflictuality (which can go up to physical violence). In impoverished environments with low education level, the socio-cultural disadvantaged, such behaviors are rather normal in the community mentality. [7]

\section{Family as Educational Instance - Roles, Relationships, Responsibility and Impact in the "network" of Educational Influences Specific to Romanian Society}

There are a fairly weak intergenerational transmission capacity values and cultural patterns. The actual family "plays" its role of education in a vast and often "obscure", underground network and alternative models of influences, including children who can and must choose and where the family model is not always a preferred. [9]

Possession of the social cultural capital of the parents is not enough. Culture (or cultures) juvenile promotes a gregarious spirit, collectivist-oriented folding of the rules and conventions (of course, a rule other than those covered by parents). There is a gap in communication between parents and children. Parents think that the group of friends is the main factor of negative influence on the child. The efforts the children do for the academic success and social aspirations are influenced by the parents. There are subjects need to be supported through specific programs tailored to overcome conflicts.

\section{Recommendations on the Education of Parents and Future}

Emphasis on public policy measures is needed in the following areas: public debate of the role of parents and the role of teachers, boundaries and limits family education in school education, the need for partnership in setting common goals of the school and the family relations of cooperation in mobilizing the necessary resources to improve education; sensitization of parents, teachers, professionals (psychologists, sociologists, educators), policy makers need to improve the education of family and school education, including through collaboration between family, school and other educational institutions; media coverage and valuing stronger parenting (including those on informal and non-formal - projects, parent education programs broadcasting etc.); strengthening the legal and the institutional system; boosting local authorities and non-governmental organizations for the establishment of "networks" socio-educational of "poles" [10]

Family enhancing expertise in education must aim at achieving the following objectives: conducting research and surveys transverse and longitudinal with quantitative and qualitative research methods to determine the socio-educational needs and resources real specific social groups and families; developing strategies and programs for socio-educational adequacy purposes and educational social support / social assistance to the real needs of the family; social control and participatory evaluation (with multidisciplinary teams of specialists, policy makers and administrators, beneficiaries - parents); human resource development programs for family education and parent education through the training and attracting volunteers; extending best practices and positive experiences with parental education programs conducted to present date.

\section{Conclusions}

The development of education policies on family education as a priority can be achieved in Romania through: curriculum policy - education pro family (parenthood education) of the students of final grades of compulsory education; management policies and evaluation of educational institutions - criteria, standards, indicators on education of students, school-family partnership and cooperation; political training (initial and ongoing) of the teachers, focusing on issues / themes of family sociology and ethics education educator; partnership policies aimed at specifying the framework partnership agreement between the school and family, as indirect beneficiaries through co-participation of parents and students, as direct beneficiaries, decisions regarding school life of children.

\section{REFERENCES}

[1] Hatos, Adrian Sociology of education, Iași: Polirom 
Publishing House, p. 60, 2006.

[2] Stănciulescu, E. Sociological education theories, Iași: Polirom, p. 89, 1996.

[3] Petrescu, Ana Maria Fundamentals of sociology of education, Târgoviște: Fortress Publishing House. p. 67, 2014.

[4] Stănciulescu, E. (1997) Family Sociology of Education, vol. I, Iași: Polirom, p. 104. 1997.

[5] Ciupercă, C. Modern couple - between emancipation and dissolution, Alexandria: TIPOALEX, p. 48, 2000.
[6] Baran-Pescaru, A. The family today. A socio-pedagogical perspective, Bucharest: Aramis Publishing House, p. 91, 2004.

[7] Mihăilescu, I. Family in European societies, Bucharest: University of Bucharest, p. 67, 1991.

[8] Pescaru, Maria Social protection of family and child, Craiova: Sitech, p. 78, 2014.

[9] Vrășmaș, E.A. Counseling and parenting, Bucharest: Aramis, p. 123, 2002.

[10] Zamfir, C., Vlăsceanu, L. Dictionary of sociology, Bucharest: Babel, pp. 129-187 1993. 